\title{
Beneficial role of extremophilic microbes for plant health and soil fertility
}

\author{
Ajar Nath Yadav* \\ Department of Biotechnology, Microbial Biotechnology Laboratory, Akal College of Agriculture, Eternal University, \\ Baru Sahib, Sirmour, India
}

Accepted on November 4, 2017

\section{Perspective}

The Plant microbiomes have capability of colonizing the rhizosphere, phyllosphere and internal tissues for different plant parts. The plant microbiomes (epiphytic, endophytic, and rhizospheric) have ability to produce phytohormones, solubilize nutrients, and antagonistic against pathogens. The plant associated microbes have been isolated from plant growing under the diverse abiotic stresses conditions and these extremophilic microbes help in plant growth promotion and adaptations under harsh environments of temperatures, salinity, $\mathrm{pH}$ and drought stresses. The microbes isolated from plant growing under different abiotic stresses are term as plant associated extremophilic microbes. The plant associated extremophiles have been reported from all three domain archaea, bacteria and eukarya of different phylum/groups e.g. Actinobacteria, Ascomycota, Bacteroidetes, Basidiomycota, Crenarchaeota, Euryarchaeota, Firmicutes and Proteobacteria $(\alpha / \beta / \gamma / \delta)$. The microbes possess the multifarious plant growth promoting attributes and these efficient and potential microbes may be applied as biofertilizers for crops improvements and soil health for sustainable agriculture. The microbes isolated from different plants growing under the abiotic stresses conditions of temperature, salinity, $\mathrm{pH}$ and water deficiency are said to be psychrophiles $\left(-2^{\circ} \mathrm{C}\right.$ to $\left.20^{\circ} \mathrm{C}\right)$, thermophiles $\left(60^{\circ} \mathrm{C}\right.$ to $\left.115^{\circ} \mathrm{C}\right)$, halophiles $(2-5 \mathrm{M})$, acidophiles $(\mathrm{pH}<4)$, alkaliphiles $(\mathrm{pH}>9)$ and xerophiles (water potential $0.75 \mathrm{kP}_{\mathrm{a}}$ ) [1]. Extreme habitats/niches represent unique ecosystems which harbour novel biodiversity with potential adaptations ability to diverse stresses. In order to survive under such extreme conditions, these organisms referred to as extremophiles, have developed adaptive features which permits them to grow optimally under one or more environmental extremes, while poly-extremophiles grow optimally under multiple conditions [2].

Today, it is a widely accepted fact that certain strains of rhizospheric bacteria, referred to as plant growth promoting bacteria (PGPB), stimulate plant growth and fitness. Thanks to the knowledge of communication signals between rhizosphere organisms, we are able to understand, at least partially, the PGP mechanisms of action. Microbial diversity associated with crops is considered important for maintaining for the sustainability of agriculture production systems. A microbe helps plant for growth, yield and adaptation. Microbes associated with crops could be classified into three groups, e.g. rhizospheric, phyllospheric and endophytic. The rhizosphere is the zone of soil influenced by roots through the release of substrates that affect microbial activity [3]. A number of microbial species have been reported associated with the plant rhizosphere belonging to genera Azospirillum, Arthrobacter, Burkholderia, Bacillus, Paenibacillus, Burkholderia,
Enterobacter, Methylobacterium, Pseudomonas, Rhizobium and Serratia [4-6]. The epiphytic microbes have been reported from different phyllospheric part of plants. The phyllosphere is common niches for synergism between different potential microbes and plant. The epiphytic microbes are most adaptive in nature as they tolerate high temperature $\left(40^{\circ} \mathrm{C}-55^{\circ} \mathrm{C}\right)$ and $\mathrm{UV}$ radiation. The microbe related to different genera such Agrobacterium, Methylobacterium, Pantoea and Pseudomonas have been reported in the phyllosphere of different crops growing in normal as well as harsh environmental conditions [7-9]. The endophytic microbes are referred to those microbes, which colonizes in the interior of the plant parts, viz: root, stem or seeds without causing any harmful effect on host plant. These microbes have been isolated from a variety of plants including wheat [10]; Rice, Soybean, Pea, Common Bean, Chickpea and Pearl millet [11]. The endophytic microbial species belonging to different genera including Achromobacter, Azoarcus, Burkholderia, Enterobacter, Gluconoacetobacter, Herbaspirillum, Klebsiella, Microbiospora, Micromomospora, Nocardioides, Pantoea, Planomonospora, Pseudomonas, Serratia, Streptomyces and Thermomonospora have been sorted out from different host plants [6,12-14].

The microbes associated with plants can be enumerated using serial dilution techniques with help of different nutrientionla combination in form of diverse selective and complex media e.g. nutrient agar for heterotrophic, trypticase soya agar for Arthrobacter, soil extract agar for soil-specific microbes, Jensen's agar for $\mathrm{N}_{2}$-fixing bacteria, King'B agar for Pseudomonads, yeast extract mannitol agar for Rhizobium, Modified Dobereiner medium and Luria Bertani agar for endophytic microbes [3]. For identification of microbes, Genomic DNA can be isolated using Zymo Research Fungal/ Bacterial DNA MicroPrep $^{\mathrm{TM}}$ following the standard protocol prescribed by the manufacturer. Different primers can be used for amplification of 16S rRNA gene for archaea and bacteria while 18S rRNA gene for fungi. PCR amplified 16S/18S rRNA genes have to purified and sequenced [15]. The partial $16 \mathrm{~S}$ or $18 \mathrm{~S}$ rRNA gene sequences should be compared with sequences available in the NCBI database.

Biotechnology has opened up new possibilities concerning the application of beneficial microbes to the soil for the promotion of plant growth and the biological control of soil-borne pathogens. The nutritional and environmental requirements of these microbes are very diverse. The microbial inoculation has a much better stimulatory effect on plant growth in nutrient deficient soil than in nutrient rich soil. An understanding of microbial diversity perspectives in agricultural context is important and useful to arrive at measures that can act as indicators of soil quality and plant productivity. The different groups of microbes have been reported as plant associated such 
as archaea, eubacteria and fungi, which included different phylum mainly:Acidobacteria, Actinobacteria, Ascomycota, Bacteroidetes, Basidiomycota, Deinococcus-Thermus, Euryarchaeota, Firmicutes and Proteobacteria.Overall the distribution of microbes varied in all bacterial phyla, Proteobacteria were most dominant followed by Actinobacteria. Least number of microbes was reported from phylum Deinococcus-Thermus and Acidobacteria followed by Bacteroidetes [16-20].

Soil salinity is an important limiting factor for agricultural crops especially in arid and semi-arid regions of the world. Although many technologies have been implicated in the improvement of salt tolerance, only PGP microbes-elicited plant tolerance against salt stress has been previously studied [7,21-23]. Microbes associated crops have a high potential for agriculture because they can improve plant growth, under limiting or stress conditions of temperatures. The microorganisms from extreme environments are of particular importance in global ecology since the majority of terrestrial and aquatic ecosystems of our planet are permanently or seasonally submitted to cold temperatures. Microorganisms capable of coping with low temperatures are widespread in these natural environments where the often represent the dominant flora and they should therefore be regarded as the most successful colonizers of our planet. In the past few years, the diversity of microorganisms inhabiting cold environments has been extensively investigated [24-27]. Drought stress limits the growth and productivity of crops, particularly in arid and semi-arid areas [6-7,28]. Alkaline/Acidic environments are also hot spot for microbial diversity with plant growth promoting attributes. Many acidotolerant bacterial genera have been reported from plant growing in acidic environments. The different groups of microbes have a potential role in different possess and applications e.g. Archaea for P-solubilization and mobilization [23], bacteria and cyanobacteria as probiotics [29,30], biodegradation at low temperature [31], cold adapted enzymes (lipase, amylase, protease, cellulase and xylanase) for industrial applications [24]; anti-freezing compounds production from psychrophilic and psychrotrophic microbes $[25,32]$ and microbes with multifarious PGP attributes for plant growth and soil helath for sustainable agriculture [33].

In conclusion, plants play an important role in selecting and enriching the types of bacteria by the constituents of their root exudates. Thus, depending on the nature and concentrations of organic constituents of exudates, and the corresponding ability of the microbes to utilize these as sources of energy, the microbial community develops in the interaction as epiphytic/ endophytic/rhizospheric. Microbes associated with crops are of agriculturally important as they can enhance plant growth; improve plant nutrition through biological $\mathrm{N}_{2}$-fixation and other mechanisms. Microbes may increase crop yields, remove contaminants, inhibit pathogens, and produce fixed nitrogen or novel substances. The growth stimulation by microbes can be a consequence of biological $\mathrm{N}_{2}$-fixation, production of phytohormones, such as IAA and cytokines; biocontrol of phytopathogens through the production of antifungal or antibacterial agents, siderophores production, nutrient competition and induction of acquired host resistance, or enhancing the bioavailability of minerals $[11,34,35]$. The need of today's world is high output yield and enhanced production of the crop as well as fertility of soil to get in an eco-friendly manner. Hence, the research has to be focused on the new concept of microbial engineering based on favorably partitioning of the exotic biomolecules, which create a unique setting for the interaction between plant and microbes. Future research in microbes will rely on the development of molecular and biotechnological approaches to increase our knowledge of microbes and to achieve an integrated management of microbial populations of endophytic, epiphytic and rhizospheric.

\section{Acknowledgement}

The authors duly acknowledge the Department of Biotechnology, Akal College of Agriculture and Vice Chancellor, Eternal University for providing the motivation and research infrastructure.

\section{References}

1. Yadav AN, Verma P, Kumar M, et al. Diversity and phylogenetic profiling of niche-specific Bacilli from extreme environments of India. Ann Microbiol. 2015;65(2): 611-29.

2. Saxena AK, Yadav AN, Rajawat MVS, et al. Microbial diversity of extreme regions: An unseen heritage and wealth. Indian J Plant Genet Resour. 2016;29(3):246-48.

3. Verma P, Yadav AN, Kumar V, et al. Beneficial PlantMicrobes Interactions: Biodiversity of Microbes from Diverse Extreme Environments and its Impact for Crops Improvement. Springer Nature, Singapore. 2017.

4. Xie H, Pasternak JJ, Glick BR. Isolation and Characterization of Mutants of the Plant Growth-Promoting Rhizobacterium Pseudomonas putida GR12-2 That Overproduce Indoleacetic Acid. Curr Microbiol. 1996;32(2):67-71.

5. Lavania M, Chauhan PS, Chauhan S, et al. Induction of plant defense enzymes and phenolics by treatment with plant growth- Promoting rhizobacteria Serratia marcescens NBRI1213. Curr Microbiol. 2006;52(5):363-68.

6. Verma P, Yadav AN, Kazy SK, et al. Evaluating the diversity and phylogeny of plant growth promoting bacteria associated with wheat (Triticum aestivum) growing in central zone of India. Int J Curr Microbiol Appl Sci. 2014;3(5):432-47.

7. Verma P, Yadav AN, Khannam KS, et al. Appraisal of diversity and functional attributes of thermotolerant wheat associated bacteria from the peninsular zone of India. Saudi J Biol Sci. 2016.

8. Meena KK, Kumar M, Kalyuzhnaya MG, et al. Epiphytic pink-pigmented methylotrophic bacteria enhance germination and seedling growth of wheat (Triticum aestivum) by producing phytohormone. Antonie van Leeuwenhoek. 2012;101(4):777-86. 
9. Nutaratat P, Srisuk N, Arunrattiyakorn P, et al. Plant growth-promoting traits of epiphytic and endophytic yeasts isolated from rice and sugar cane leaves in Thailand. Fungal Biol. 2014;118(8):683-94.

10. Verma P, Yadav AN, Kazy SK, et al. Elucidating the diversity and plant growth promoting attributes of wheat (Triticum aestivum) associated acidotolerant bacteria from southern hills zone of India. Natl J Life Sci. 2013;10(2): 219-27.

11. Suman A, Yadav AN, Verma P. Endophytic Microbes in Crops: Diversity and Beneficial impact for Sustainable Agriculture. In: Singh D, Abhilash P, Prabha R(eds) Microbial Inoculants in Sustainable Agricultural Productivity, Research Perspectives. Springer-Verlag, India. 2016;117-43.

12. Ryan RP, Germaine K, Franks A, et al. Bacterial endophytes: recent developments and applications. FEMS Microbiol Lett. 2008;278(1):1-9.

13. Hallmann J, Quadt-Hallmann A, Mahaffee W, et al. Bacterial endophytes in agricultural crops. Can J Microbiol. 1997;43(10):895-914.

14. Verma P, Yadav AN, Khannam KS, et al. Assessment of genetic diversity and plant growth promoting attributes of psychrotolerant bacteria allied with wheat (Triticum aestivum) from the northern hills zone of India. Ann Microbiol. 2015;65(4):1885-99.

15. Yadav AN, Verma P, Sachan SG, et al. Psychrotrophic Microbes: Molecular Diversity and Beneficial Role in Plant Growth Promotion. In: Panpatte D, Jhala Y, Shelat H et al. (eds) Microorganisms for Green Revolution: Microbes for sustainable agro-ecosystem. Springer Nature Singapore. 2017;2.

16. Yadav AN, Sachan SG, Verma P, et al. Prospecting cold deserts of north western Himalayas for microbial diversity and plant growth promoting attributes. J Biosci Bioeng. 2015;119(6):683-93.

17. Yadav AN, Verma P, Sachan SG, et al. Biodiversity and biotechnological applications of psychrotrophic microbes isolated from Indian Himalayan regions. EC Microbiol. 2017;1:48-54.

18. Sun L, Qiu F, Zhang X, et al. Endophytic bacterial diversity in rice (Oryza sativa L.) roots estimated by $16 \mathrm{~S}$ rDNA sequence analysis. Microb Ecol. 2008;55(3):415-24.

19. Yadav AN, Verma P, Singh B, et al. Plant Growth Promoting Bacteria: Biodiversity and Multifunctional Attributes for Sustainable Agriculture. Adv Biotechnol Microbiol. 2017;5(5):1-16.

20. Sahay H, Yadav AN, Singh AK, et al. Hot springs of Indian Himalayas: Potential sources of microbial diversity and thermostable hydrolytic enzymes. 3 Biotech. 2017;7(2): $1-11$.

21. Yadav AN, Verma P, Kaushik R, et al. Archaea endowed with plant growth promoting attributes. EC Microbiol. 2017;8(6):294-98.

22. Paul D, Nair S. Stress adaptations in a plant growth promoting rhizobacterium (PGPR) with increasing salinity in the coastal agricultural soils. J Basic Microbiol. 2008;48(5):378-84.

23. Yadav AN, Sharma D, Gulati S, et al. Haloarchaea endowed with phosphorus solubilization attribute implicated in phosphorus cycle. Sci Rep. 2015;5:12293.

24. Yadav AN, Sachan SG, Verma P, et al. Cold active hydrolytic enzymes production by psychrotrophic Bacilli isolated from three sub-glacial lakes of NW Indian Himalayas. J Basic Microbiol. 2016;56:294-307.

25. Singh RN, Gaba S, Yadav AN, et al. First High quality draft genome sequence of a plant growth promoting and Cold Active Enzymes producing psychrotrophic Arthrobacter agilis strain L77. Stand Genomic Sci. 2016;11(1):54.

26. Yadav AN, Verma P, Kumar V, et al. Extreme cold environments: A suitable niche for selection of novel psychrotrophic microbes for biotechnological applications. Adv Biotechnol Microbiol. 2017;2(2):1-4.

27. Mishra PK, Joshi P, Bisht SC, et al. Cold-Tolerant Agriculturally Important Microorganisms. In: Maheshwari D. (eds) Plant Growth and Health Promoting Bacteria. Springer Berlin Heidelberg, Berlin, Heidelberg. 2010;273-96.

28. Lim J-H, Kim S-D. Induction of Drought Stress Resistance by Multi-Functional PGPR Bacillus licheniformis K11 in Pepper. Plant Pathol J. 2013;29(2):201-8.

29. Panjiar N, Mishra S, Yadav AN, et al. Functional Foods from Cyanobacteria: An Emerging Source for Functional Food Products of Pharmaceutical Importance. In: Gupta VK, Treichel H, Shapaval VO, et al. (eds) Microbial Functional Foods and Nutraceuticals. John Wiley \& Sons, USA. 2017;21-37.

30. Yadav AN, Kumar R, Kumar S, et al. Beneficial microbiomes: Biodiversity and potential biotechnological applications for sustainable agriculture and human health. J Appl Biol Biotechnol. 2017;5(6):1-13.

31. Shukla L, Suman A, Yadav AN, et al. Syntrophic microbial system for ex-situ degradation of paddy straw at low temperature under controlled and natural environment. J Appl Biol Biotech. 2016;4(2):30-7.

32. Yadav AN. Bacterial diversity of cold deserts and mining of genes for low temperature tolerance. Ph.D. Thesis, Indian Agricultural Research Institute, New Delhi and Birla Institute of Technology, Ranchi. 2015;234.

33. Verma P, Yadav AN, Khannam KS, et al. Molecular diversity and multifarious plant growth promoting attributes of Bacilli associated with wheat (Triticum aestivum L.) rhizosphere from six diverse agro-ecological zones of India. J Basic Microbiol. 2015;56(1):44-58.

34. Kumar V, Yadav AN, Verma P, et al. $\beta$-Propeller phytases: Diversity, catalytic attributes, current developments and potential biotechnological applications. Int $\mathrm{J}$ Biol Macromolec. 2017;98:595-609.

35. Yadav AN, Sachan SG, Verma P, et al. Bioprospecting of plant growth promoting psychrotrophic Bacilli from cold desert of north western Indian Himalayas. Indian J Exp Biol. 2016;54(2):142-50. 
Citation: Yadav AN. Beneficial role of extremophilic microbes for plant health and soil fertility. J Agric Sci Bot 2017;1(1):30-33.

\section{* Correspondence to:}

Yadav AN

Department of Biotechnology

Eternal University, Baru Sahib,

Sirmour-173101, India

Tel: +91-9882545085

E-mail: ajar@eternaluniversity.edu.in 